\title{
BUDGET HOTEL \\ Dengan Pendekatan Arsitektur Hemat Energi Di COLOMADU, KARANGANYAR
}

\author{
Yusnia Satyawati Hardiningtyas, Bonifasius Heru Santosa Soemarno, Amin Sumadyo \\ Program Studi Arsitektur \\ Fakultas Teknik \\ Universitas Sebelas Maret Surakarta \\ Email : yusniisatya@gmail.com
}

\begin{abstract}
Colomadu is a locality of Karanganyar Regency located quite far apart from the Karanganyar Regency (exclave). Existing issues in the region of Colomadu becoming the background of planning and designing Budget Hotel in Colomadu with Energy Saving Architecture approach, as for instances, the existence of competition between hotels; a tendency of the tourist to stay in affordable lodgments with comfortable facilities; most of the hotels in Colomadu have not applied the concept of energy saving; as well as the Colomadu area good prospects and strategic location Budget Hotel since it is close to the International Airport of Adi Sumarmo and bounded by regions with capability to support activities in the Budget Hotel. The problem of the design is how to implement energy saving concept (focus on lighting and air conditioning system) on the building as an effort to minimize the expenses of energy use, but the facilities granted stay comfortable and affordable. The purpose of this design is getting a building design that provides lodging facilities with affordable, comfortable, and apply the concept of energy saving. The method used is the method of designing architecture with the Energy Saving Architecture approach. The results obtained, i.e. the design Budget Hotel with Energy Saving Architecture approach which is applied to the lighting and air conditioning system, such as determining the position of the openings and performing control of sunlight by providing massive walls, overhang, and secondary skin on the exterior of the building simulated with Autodesk Ecotect Analysis 2011 as well as the use of the roller blind or curtains in interior building, simulation system for Dialux 4.12 artificial lighting, and simple calculations to determine the system of artificial air conditioning (AC).
\end{abstract}

Keywords: Autodesk Ecotect Analysis 2011, Budget Hotel, Dialux 4.12, Energy Saving Architecture, Lighting and Air Conditioning System.

\section{PENDAHULUAN.}

Perkembangan wisatawan di Soloraya yang kian meningkat membuat jumlah penginapan atau hotel juga semakin meningkat dengan berbagai tipe hotel. Namun, saat ini wisatawan lebih memilih sebuah penginapan atau hotel dengan harga terjangkau, tetapi sudah memiliki fasilitas memadai dan nyaman apalagi bagi wisatawan yang tujuan utamanya adalah untuk bekerja atau melakukan bisnis (bussiness tourist) atau travelling saja. Pemilihan lokasi di daerah Colomadu dipertimbangkan dengan berbagai hal, seperti masih sedikitnya jumlah hotel di Colomadu dengan konsep harga terjangkau dan fasilitas memadai (Budget Hotel) sehingga saat ini Budget Hotel memiliki prospek yang cukup tinggi di Colomadu; jumlah lahan belum terbangun masih banyak; adanya rencana
Pemerintah Karanganyar untuk menjadikan Colomadu sebagai daerah moderen dengan mengembangkan kawasan Jalan Adi Sucipto dan Adi Sumarmo melalui industri kecil (perumahan, hotel, kantor, perdagangan); dan lain-lain.

ORB (Objek Rancang Bangun) dengan tipe Budget Hotel ini direncanakan menerapkan konsep hemat energi sehingga mampu mendukung konsep utama dari hotel, yaitu memberikan harga yang terjangkau, tetapi fasilitas yang diberikan sudah nyaman dan memadai tanpa mengurangi serta membatasi kegiatan. Menurut Sulhi, 2002 (dalam Arif Uddin 2009), berdasarkan penelitian dan pengalaman dari Ir. Jimmy Priatman, M.Arch, jika konsep hemat energi direncanakan sejak awal, energi yang diirit bisa mencapai $45 \%$. Tetapi, jika diterapkan 
saat gedung sudah beroperasi, penghematan yang dilakukan tidak lebih dari $15 \%$. Konsep hemat energi dapat diterapkan pada berbagai aspek, tetapi aspek yang akan diterapkan pada ORB lebih fokus pada sistem pencahayaan dan penghawaan saja.

Menurut Chris Elder, 2010 (dalam Dwi Kusumastuty 2013), Budget Hotel merupakan sebuah hotel tanpa fasilitas restoran atau fasilitas banquet, dengan layanan dan fasilitas yang ditawarkan untuk hotel ini terbilang sederhana. Namun, dalam 10 tahun terakhir, layanan dan fasilitas telah berkembang, dan saat ini jenis fasilitas Budget Hotel dapat mencakup bussiness center, ruang kebugaran, fasilitas laundry tamu, dapur pantry, kolam renang indoor atau outdoor dan whirl pool, serta ruang rapat kecil (Dwi Kusumastuty, 2013). Jadi, untuk mengimbangi perkembangan hotel saat ini, khususnya tipe Budget Hotel maka diberikan fungsi penunjang, seperti penyediaan meeting room, toko souvenir, dan jasa laundry. Selain itu, berlakunya semboyan "only pay what you use" menjadikan tipe hotel ini berbeda dengan hotel-hotel lainnya. Perbedaan yang lebih mencolok lagi, yakni pelayanan staff. Staff hanya melayani pada bagian tertentu saja, seperti chek in dan check out karena memang tidak ada layanan kamar sehingga jumlah staff dapat diminimalisir, tetapi tetap mempertimbangkan kenyamanan tamu hotel. Perancangan ORB ini diharapkan mampu memberikan sebuah penginapan dengan harga terjangkau yang dilengkapi dengan fasilitas yang memadai tanpa mengurangi kenyamanan dan kegiatan, peduli lingkungan, serta memanfaatkan unsur budaya lingkungan sekitar yang akan diaplikasikan pada toko souvenir mengingat pelaku utama yang akan menginap adalah bussinessman yang tidak mempunyai banyak waktu luang untuk pergi liburan ke kota atau daerah yang bersangkutan.

\section{METODE}

Berdasarkan konsep perencanaan dan perancangan, Budget Hotel yang direncanakan menerapkan Arsitektur Hemat Energi yang fokus pada sistem pencahayaan dan penghawaan. Pemanfaatan iklim setempat sebagai sistem pencahayaan dan penghawaan alami memberikan resiko terhadap desain bangunan, seperti panasnya sinar matahari dan pergerakan angin yang terlalu kencang dan besar. Oleh karena itu, diperlukan sistem kendali iklim, baik pada eksterior maupun interior. Sistem kendali tersebut, antara lain (eksterior) dinding masif, overhang, secondary skin, vegetasi dan lain-lain yang didesain sedemikian rupa dan disimulasikan dengan Autodesk Ecotect Analysis 2011 untuk mendapatkan posisi dan desain bukaan serta kendali iklim yang tepat; (interior) tirai atau gorden dan roller blind. Selain itu, penentuan kebutuhan sistem pencahayaan dan penghawaan buatan juga penting. Oleh karena itu, digunakan Dialux 4.12 dalam merancang sistem pencahayaan buatan dan dilakukan perhitungan sederhana dalam menentukan kebutuhan AC sebagai sistem penghawaan buatan.

\section{ANALISIS}

\section{A. Analisis Peruangan}

Kebutuhan ruang yang muncul merupakan pertimbangan dari kegiatan yang dilakukan di dalam Budget Hotel karena ruang-ruang yang muncul tersebut nantinya digunakan untuk mewadahi segala kegiatan yang ada di dalam Budget Hotel.

Tabel 1. Kebutuhan Ruang Pengelola Hotel

\begin{tabular}{|c|c|c|}
\hline Pelaku & Jenis Kegiatan & Ruang \\
\hline $\begin{array}{l}\text { Pengelola } \\
\text { (orang } \\
\text { yang } \\
\text { bekerja } \\
\text { di dalam } \\
\text { hotel) }\end{array}$ & 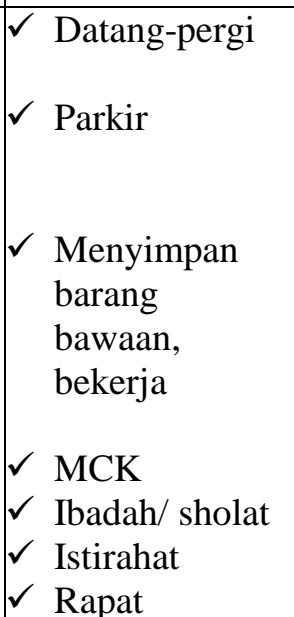 & $\begin{array}{l}\text { Side/service } \\
\text { Entrance } \\
\text { Tempat } \\
\text { Parkir } \\
\text { Pengelola } \\
\text { R. Pengelola, } \\
\text { R. Staff, } \\
\text { Front Office, } \\
\text { Pos Satpam, } \\
\text { dll } \\
\text { Toilet } \\
\text { Musholla } \\
\text { Pantry } \\
\text { R. Rapat }\end{array}$ \\
\hline
\end{tabular}

Dari Tabel 1. dapat diketahui ruang-ruang yang dibutuhkan untuk mewadahi kegiatan pengelola hotel yang ada di dalam ORB.

Tabel 2. Kebutuhan Ruang Tamu Hotel 


\begin{tabular}{|c|c|c|}
\hline $\begin{array}{l}\text { Pelaku } \\
\text { Kegiatan }\end{array}$ & Jenis Kegiatan & Ruang \\
\hline $\begin{array}{l}\text { Tamu } \\
\text { Hotel }\end{array}$ & $\begin{array}{ll}\checkmark & \text { Datang-pergi } \\
\checkmark & \text { Parkir } \\
\vee & \text { Check in-out, } \\
& \text { menunggu- } \\
& \text { duduk } \\
\checkmark & \text { Mengambil } \\
& \text { uang } \\
\checkmark & \text { Mengakses } \\
& \text { internet } \\
\checkmark & \text { Istirahat } \\
\checkmark & \text { MCK } \\
\checkmark & \text { Bisnis/ rapat } \\
\checkmark & \text { Sarapan } \\
\checkmark & \text { Membeli oleh- } \\
& \text { oleh/ souvenir }\end{array}$ & $\begin{array}{l}\text { Main Entrance } \\
\text { Tempat Parkir } \\
\text { Front Office, } \\
\text { Lobby } \\
\text { ATM Center } \\
\text { Internet } \\
\text { Corner } \\
\text { Kamar Hotel } \\
\text { Toilet Pribadi/ } \\
\text { Toilet Hotel } \\
\text { R. Rapat } \\
\text { R. Makan } \\
\text { Toko Souvenir }\end{array}$ \\
\hline
\end{tabular}

Pada Tabel 2. terlihat ruang-ruang yang dibutuhkan untuk mewadahi kegiatan tamu hotel yang ada di dalam ORB.

B. Analisis Lokasi

Pemilihan lokasi dilakukan melalui beberapa pertimbangan yang sangat mempengaruhi prospek ORB.

a. Tujuan:

Mendapatkan lokasi yang sesuai dengan ORB dan mampu mendukung kegiatan di dalam ORB dari lingkungan sekitar yang ada di lokasi

b. Dasar Pertimbangan:

Lokasi yang strategis, terletak di tepi Jalan Adi Sucipto sehingga mudah dikenali atau dilihat oleh orang yang lewat, ukuran tapak yang mampu menampung ruang-ruang yang direncanakan, kemudahan akses jalan, bentuk tapak yang simple; faktor kenyamanan, tidak terlalu dekat dengan bandara untuk mengantisipasi suara bising yang ditimbulkan oleh pesawat; lokasi yang sehat, sistem pencahayaan dan penghawaan lingkungan sekitar bersih dan sehat; adanya rencana program dari pemerintah setempat; adanya fasilitas pendukung yang mempengaruhi kegiatan di dalam ORB.

C. Analisis Pencapaian

Pencapaian ke dalam bangunan harus mudah dilihat dan diakses serta adanya pemisahan akses keluar-masuk antara tamu dan pengelola hotel agar tidak terjadi crossing.

Tujuan: menentukan main entrane dan service entrance

1. Dasar Pertimbangan: sirkulasi tapak yang mudah diakses, arus kendaraan dan potensi jalan, tingkat keamanan dan kenyamanan, menghindari crossing.

2. Proses Analisis

Main Entrance (ME) $\bigcirc$

Mudah dijangkau dan terlihat dengan jelas. Menghadap langsung ke arah jalan untuk kemudahan sirkulasi kendaraan masuk dan ke luar tapak. Lebih diperuntukkan bagi tamu hotel.

\section{Side/service Entrance (SE) $\bigcirc$}

Tidak mengganggu keberadaan ME. Diperuntukkan sebagai sirkulasi pengelola hotel dan servis.

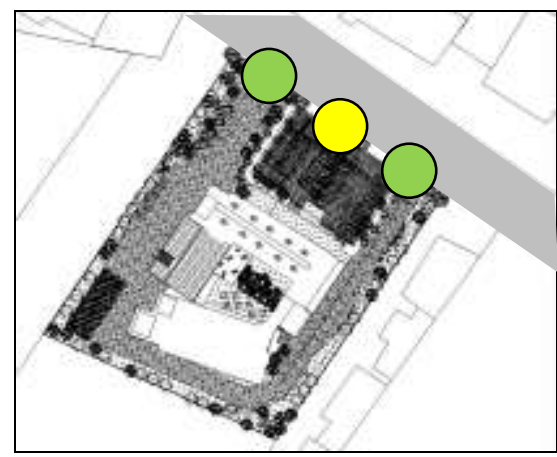

Gambar 1. Pola Pencapaian

Pada Gambar 1. terlihat pemisahan pola pencapaian untuk pengelola dan tamu hotel.

D. Analisis Pemintakatan (Penzoningan) Penentuan pemintakatan berdasarkan sifat kegiatan, tingkat kebisingan padaeksisting tapak, serta sistem pencahayaan (termasuk pembayangan) dan penghawaan alami.

1. Tujuan: menentukan mintakat (zoning) berdasarkan sifat kegiatan, tingkat kebisingan pada tapak, serta sistem pencahayaan dan penghawaan alami.

2. Dasar pertimbangan: analisis peruangan, pengolahan tapak, serta 
sistem pencahayaan dan penghawaan alami.

3. Proses analisis: menentukan mintakat terhadap persyaratan ruang dan lingkungan sekitar tapak.
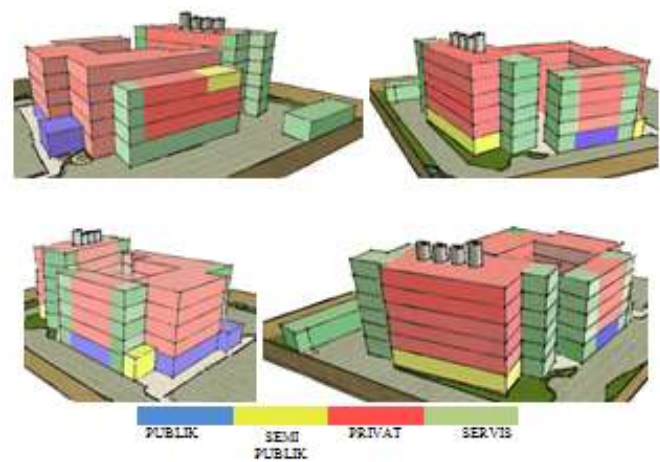

Gambar 2. Pemintakatan pada Massa Bangunan

Pada Gambar 2. pemintakatan dibedakan menjadi empat bagian, yaitu area publik, semi publik, privat, dan servis.

E. Analisis Bentuk dan Tampilan

Bangunan

1. Bentuk dan tampilan dasar massa bangunan dipertimbangkan dari pengolahan bangun dasar. Bentuk segiempat ditata dengan menggunakan pola penataan massa fingle plan dan cellery/independent block . Hal ini berdasarkan pertimbangan :

a. Fungsional dan efisiensi ruang.

b. Sifat kegiatan yang diwadahi.

c. Pengkoordinasian masingmasing kegiatan.

d. Penyesuaian terhadap fisik di tapak dan lingkungan sekitar.

e. Penataan massa dasar bangunan memperhatikan arah pergerakan matahari dan angin (iklim).

f. Estetika bentuk.

g. Dengan penggunaan pola fingle plan, tercipta sirkulasi memutar dan pola cellery/independent block mampu memperjelas fungsi masing-masing ruang serta memberikan ruang transisi yang dimanfaatkan sebagai sirkulasi sistem penghawaan alami ke dalam massa bangunan.

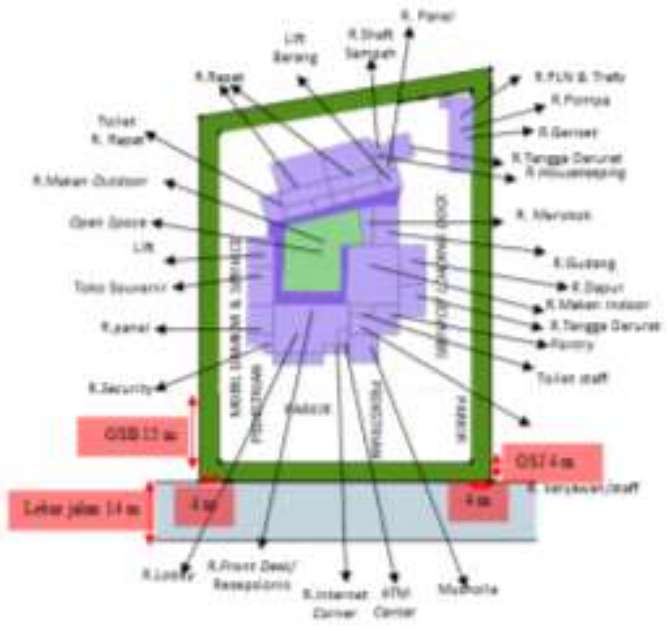

Gambar 3. Penataan Massa Dasar Bangunan

Pada Gambar 3. tata massa lantai dasar menerapkan pola penataan massa fingle plan.

\section{F. Analisis Faktor Iklim}

1. Tujuan: menentukan posisi ruang, arah, dan ukuran bukaan, simulasi sistem pencahayaan dan penghawaan alami.

2. Dasar pertimbangan: arah pergerakan matahari dan angin serta bangunan dan vegetasi di sekitar tapak.

3. Proses analisis: Arah pergerakan matahari dan angin dianalisis dengan bantuan Autodesk Ecotect Analysisi 2011 untuk mengetahui pengaruh pergerakan tersebut terhadap ORB.

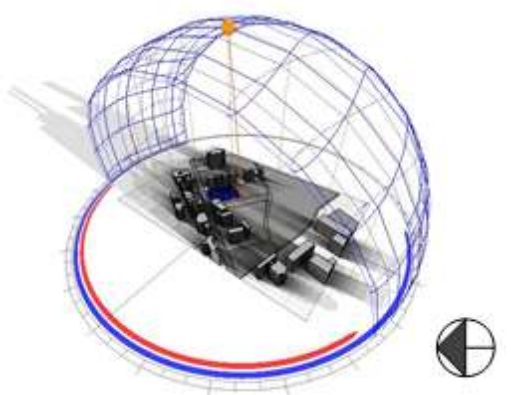

Gambar 4. Pembayangan pada Tapak Sumber: Autodesk Ecotect Analysis 2011 

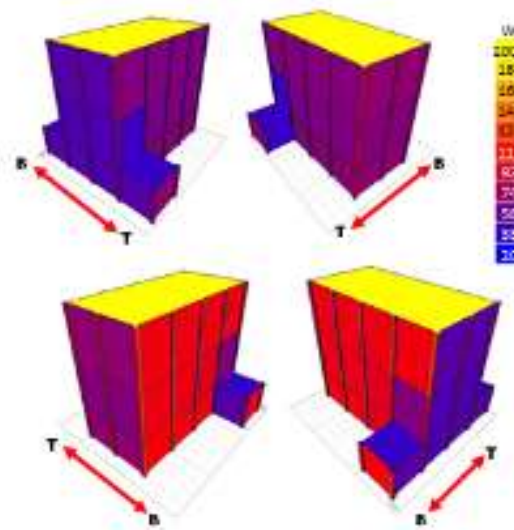

Gambar 5. Simulasi Pengaruh

Pergerakan Matahari

Sumber: Autodesk Ecotect Analysis 2011

Pada Gambar 4. simulasi pembayangan pada tapak dilakukan secara harian yang nantinya akan berpengaruh untuk menentukan peruangan, terutama ruang-ruang luar. Sedangkan, Gambar 5. merupakan simulasi solar radiation yang mungkin terjadi pada massa bangunan. Massa bangunan yang digunakan hanya ilustrasi atau contoh.

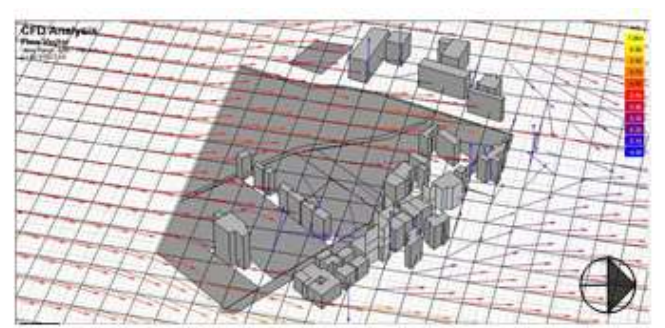

Gambar 6. Simulasi Pengaruh Pergerakan Angin pada Tapak Sumber: Autodesk Ecotect Analysis 2011

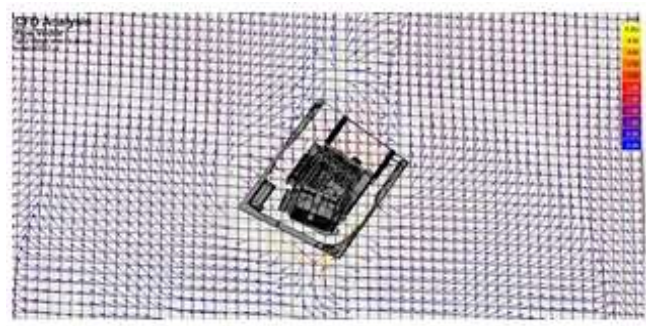

Gambar 7. Simulasi Pengaruh Pergerakan Angin pada ORB

Sumber: Autodesk Ecotect Analysis 2011 Gambar 6. menunjukkan pergerakan angin di dalam tapak yang juga dipengaruhi oleh eksisting di sekitar tapak dan Gambar 7. merupakan pengaruh pergerakan angin terhadap massa bangunan yang direncanakan.

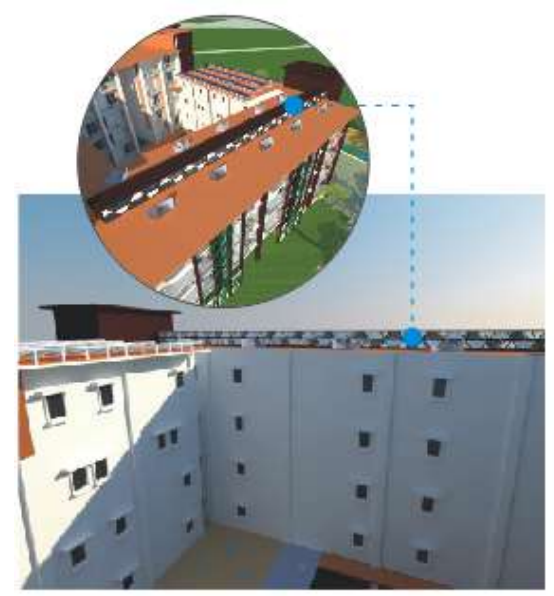

Gambar 8. Bukaan

Pada Gambar 8. terlihat bukaan horizontal berupa jendela dan bukaan vertikal berupa clerestory atau pun skylight.

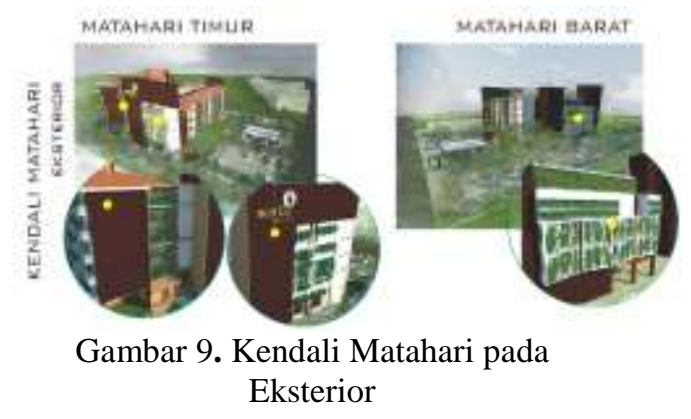

Gambar 9. menunjukkan penggunaan dinding masif, dinding berpori, dan tanaman rambat sebagai secondary skin.
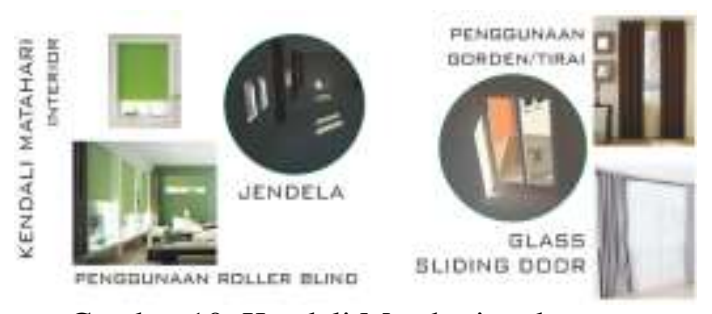

Gambar 10. Kendali Matahari pada Interior

Gambar 10. menunjukkan penggunaan roller blind sebagai kendali matahari 
pada jendela dan gorden/tirai pada pintu geser berbahan kaca.

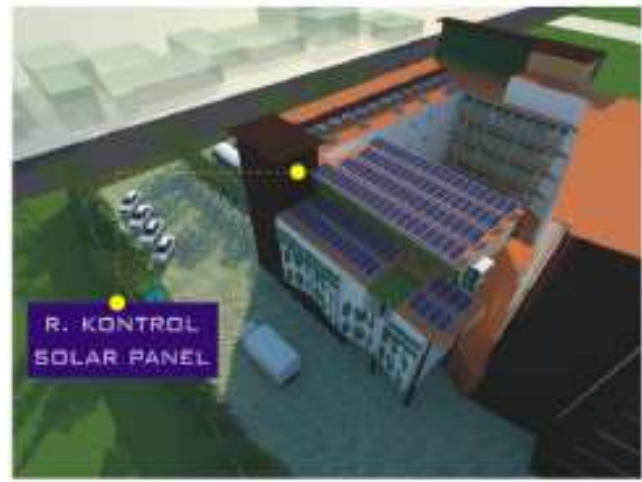

Gambar 11. Panel Surya

Gambar 11. terlihat bahwa tidak semua sinar matahari dihindari, tetapi juga dimanfaatkan sebagai sumber penghasil listrik melalui penggunaan panel surya.

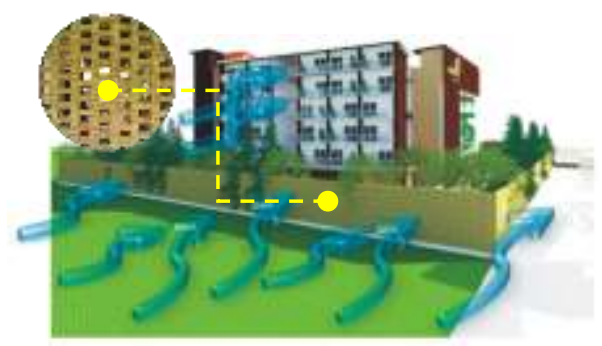

Gambar 12. Respon Terhadap Angin

Gambar 12. menunjukkan respon terhadap angin dengan menerapkan dinding berpori sebagai pagar agar angin yang datang dari selatan (belakang tapak) dapat masuk ke dalam tapak, tetapi dengan jumlah yang sedang (tidak terlalu banyak dan tidak terlalu sedikit) karena juga terdapat vegetasi yang berfungsi sebagai barrier untuk menyaring dan memecah angin.
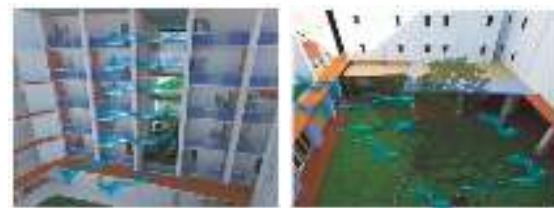

Gambar 13. Pemisahan Massa sebagai Respon Terhadap Angin

Adanya pemisahan massa bangunan agar angin dari selatan (belakang tapak) dapat masuk ke bagian tengah bangunan yang berupa taman, seperti yang terlihat pada Gambar 12. dan Gambar 13.

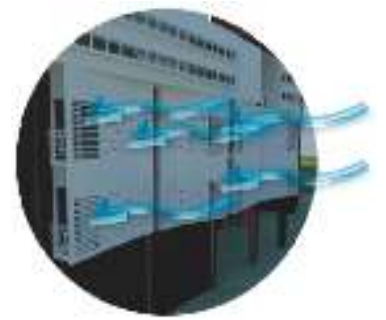

Gambar 14. Penggunaan Dinding Berpori sebagai Secondary Skin

Pada Gambar 14. Secondary skin didesain berpori (berlubang-lubang) untuk memasukkan cahaya matahari dan angin ke dalam ruang. Dinding tersebut juga diberi tanaman rambat untuk memecah angin dan menghalangi sinar matahari langsung masuk ke dalam ruang, mengingat massa ini terletak pada sisi barat.
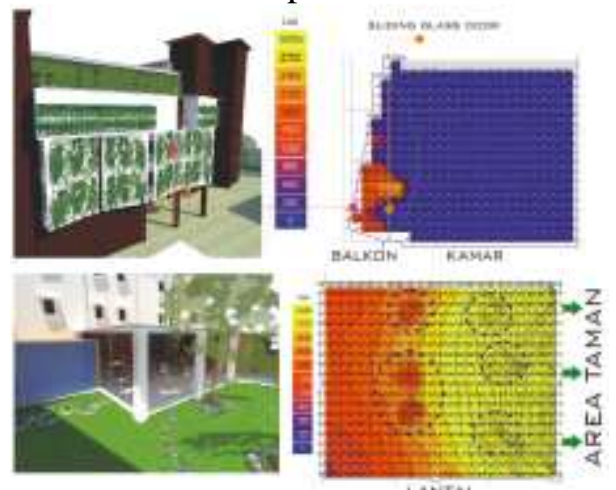

Gambar 15. Simulasi Pengaruh Matahari sebagai Sistem Pencahayaan Alami di dalam Ruang

Sumber: Autodesk Ecotect Analysis 2011

Pada Gambar 15. merupakan beberapa ruang yang telah disimulasikan dengan Autodesk Ecotect Analysis 2011 untuk mengetahui seberapa banyak cahaya matahari yang mampu masuk ke dalam ruang (dalam lux) dan dimanfaatkan sebagai sistem pencahayaan alami pada ruangan tersebut.

\section{G. Analisis Sistem Pencahayaan dan} Penghawaan Buatan

1. Tujuan: menentukan posisi dan ukuran lampu yang tepat untuk sebuah ruangan. 
2. Dasar pertimbangan: luasan dan posisi ruang.

3. Proses analisis: menggunakan Dialux 4.12 untuk menentukan sistem pencahayaan buatan dan melakukan perhitungan sederhana untuk menentukan kebutuhan AC (sistem penghawaan buatan).
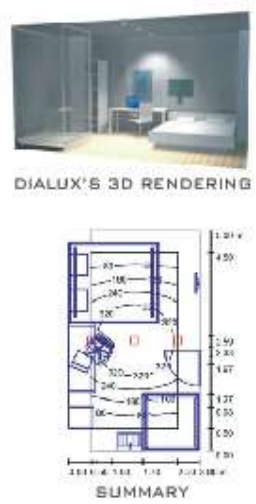

Gambar 16. Sistem Pencahayaan Buatan Sumber: Dialux 4.12

Gambar 16. merupakan salah satu ruang yang disimulasikan dengan Dialux 4.12 untuk menentukan kebutuhan lampu sebagai sistem pencahayaan buatan.

Untuk sistem penghawaan buatan, diterapkan penggunaan $\mathrm{AC}$ split, kipas angin, dan exhaust fan.

H. Analisis Vegetasi dan Elemen Pendingin

1. Tujuan: menentukan jenis dan tata letak vegetasi serta elemen pendingin.

2. Dasar pertimbangan: jenis vegetasi dan kebutuhan ruang terhadap vegetasi dan elemen pendingin tersebut.

3. Proses analisis: menentukan jenis tanaman yang sesuai dengan kebutuhan, seperti untuk peneduh, secondary skin, penunjuk arah, dan lain-lain. Elemen pendingin yang digunakan merupakan kolam ikan dan air mancur.

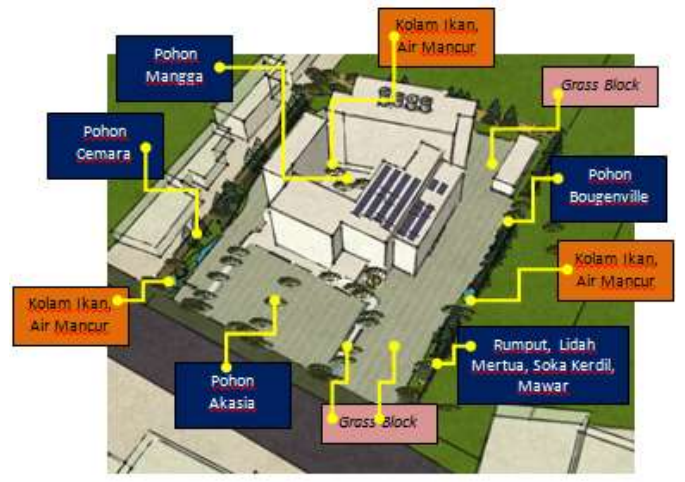

Gambar 17. Tata Letak dan Jenis Vegetasi serta Elemen Pendingin

Gambar 17. menjelaskan letak dan jenis vegetasi yang digunakan serta letak kolam ikan dan air mancur yang berfungsi sebagai elemen pendingan dan elemen estetika.

I. Analisa Struktur

Tujuan: mendapatkan sistem struktur yang sesuai dengan pembebanan.

Dasar Pertimbangan: beban yang harus didukung, kondisi tanah, bentuk dan dimensi vertikal bangunan, karakter bangunan, pengaruh terhadap lingkungan sekitar.

\section{Sub Structure dan Super Structure}

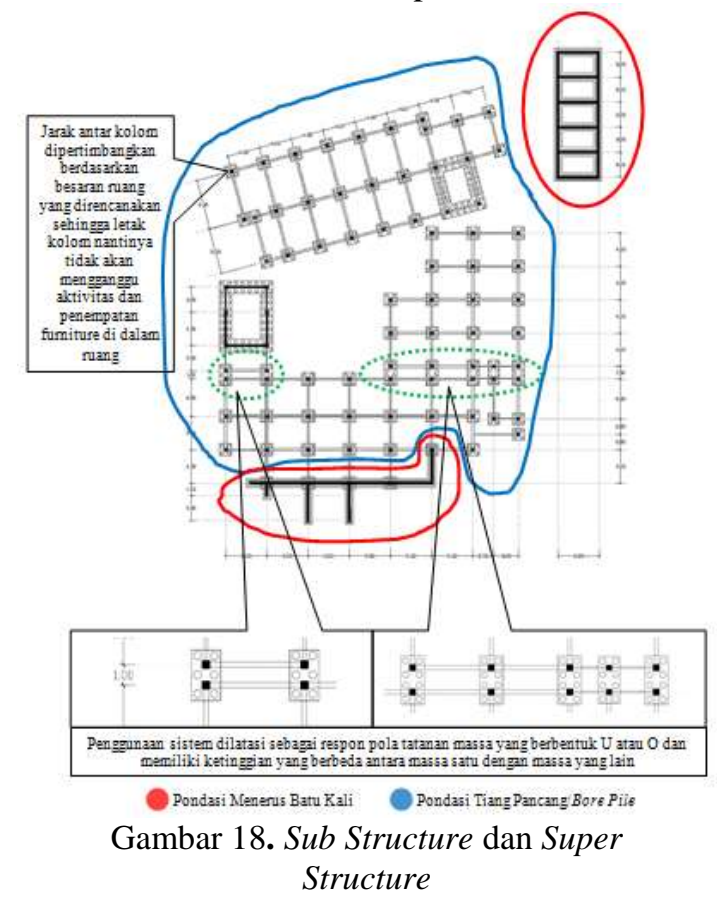


Pada gambar 18. Sub structure yang digunakan untuk massa utama menggunakan pondasi tiang pancang/bore pile. Sedangkan, massa bangunan yang difungsikan sebagai massa bangunan satu lantai menggunakan pondasi menerus batu kali. Super structure menggunakan sistem struktur rangka dengan jarak antar kolom +5 meter dan dimensi kolom 50x50 centimeter. Jarak antar kolom dipertimbangkan berdasarkan besaran ruang yang direncanakan agar tidak mengganggu kegiatan dan penempatan perabot. Sistem dilatasi diterapkan pada desain ini karena massa bangunan ini memiliki bentuk pola tatanan massa $\mathrm{U}$ atau $\mathrm{O}$ dan terdapat juga perbedaan ketinggian massa satu dengan massa yang lain. Material dinding yang digunakan sebagian besar menggunakan b-panel (Gambar 19.) yang ringan, memiliki insulasi suara yang baik, tahan gempa, tahan air, tahan rayap, tahan lembab, fleksibel, prefabrikasi, monolithic, dan mampu menghemat penggunaan listrik $20-40 \%$.

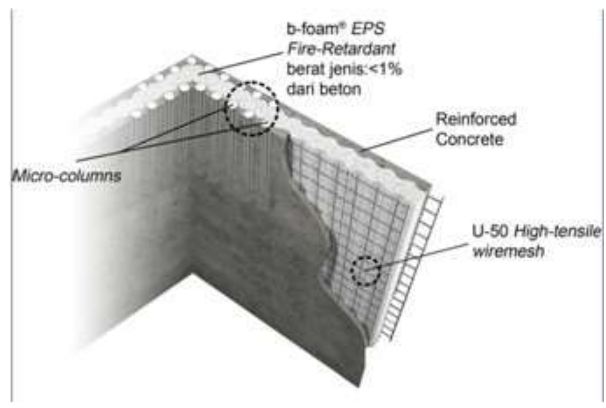

Gambar 19. Detail b-panel Sumber: www.b-panel.com

\section{Upper structure}

Pemilihan sistem struktur yang digunakan berdasarkan pertimbangan :

a. Kekuatan, keawetan, dan keamanan.

b. Fleksibel.

c. Kesesuaian dan respon terhadap iklim setempat. d. Efisiensi energi dalam proses produksi, transportasi, pemeliharaan, dan lain-lain.

Upper structure menggunakan atap dak beton untuk massa utama dan atap pelana dengan struktur rangka baja untuk massa bangunan yang difungsikan sebagai ruang mekanikal elektrikal (ruang genset, ruang pompa, ruang trafo dan listrik).

\section{KESIMPULAN (KONSEP DESAIN)}

Konsep rancangan Budget Hotel mengacu pada pendekatan Arsitektur Hemat Energi yang lebih fokus pada sistem pencahayaan dan penghawaan. ORB dirancang untuk mewadahi kebutuhan menginap dan mengikuti rencana pemerintah setempat. Pengolahan sistem pencahayaan dan penghawaan dilakukan dengan mempertimbangkan aspek estetika dan kenyamanan. Pengolahan dan penataan massa peruangan di dalam denah dapat dilihat pada Lampiran 1. dan penataan interior bangunan dapat dilihat melalui gambar potongan yang ditunjukan pada Lampiran 2.
Nama Hotel : Monggo Budget Hotel
Lokasi : Jl. Adi Sucipto, Colomadu
Luas Lahan : $\pm 4.440 \mathrm{~m}^{2}$
Luas Bangunan : $\pm 5530,045 \mathrm{~m}^{2}$
Daya Tampung : 116 kamar
Kegiatan : Fasilitas penginapan dan rapat

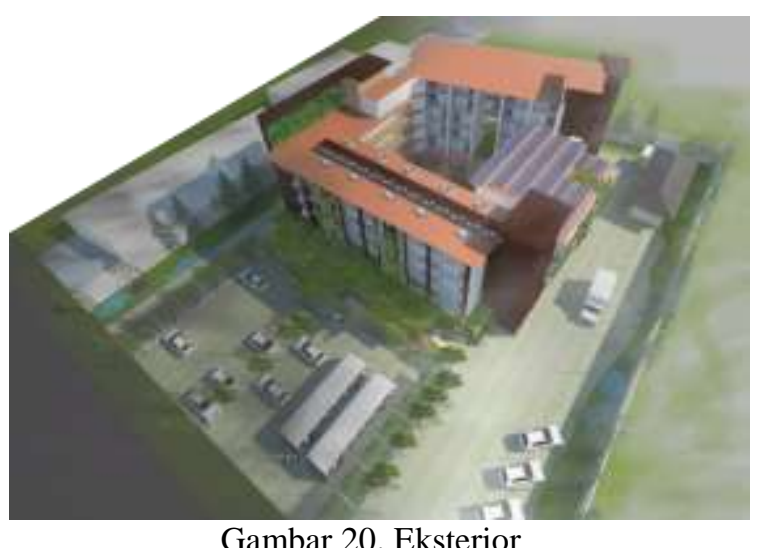

Gambar 20. merupakan eksterior bangunan yang dilihat dengan perspektif mata burung (dari atas) yang menunjukan desain bangunan dan pengolahan tapak di sekitar bangunan. 
Desain interior ORB mempertimbangkan penerapan konsep Arsitektur Hemat Energi, seperti penempatan bukaan, pemilihan warna dan material, pemberian gambar poster pada dinding kamar tidur, dan lain-lain.

Pada Gambar 21. dan Gambar 22., poster yang menghiasi dinding kamar berisi tentang himbauan untuk menghemat penggunaan energi dan melindungi serta melestarikan lingkungan sekitar.

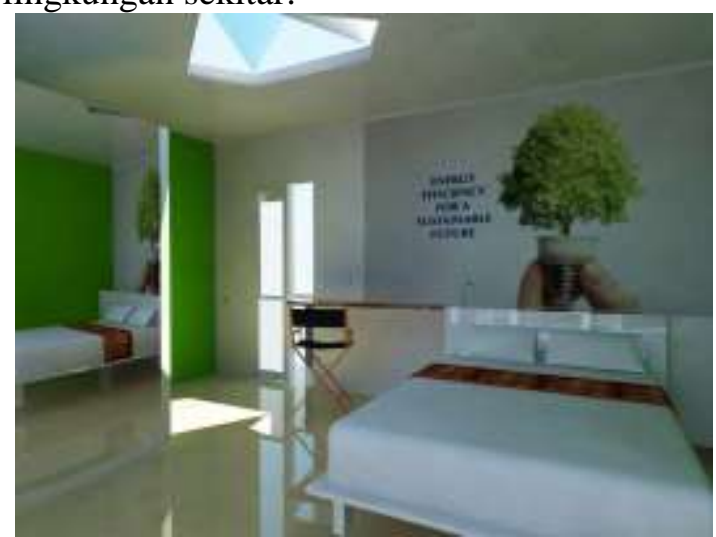

Gambar 21. Interior Double Bed Room

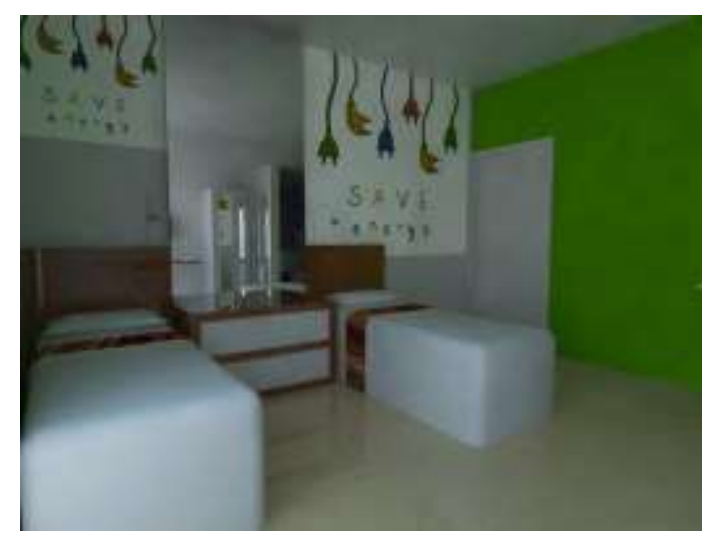

Gambar 22. Interior Twin Bed Room

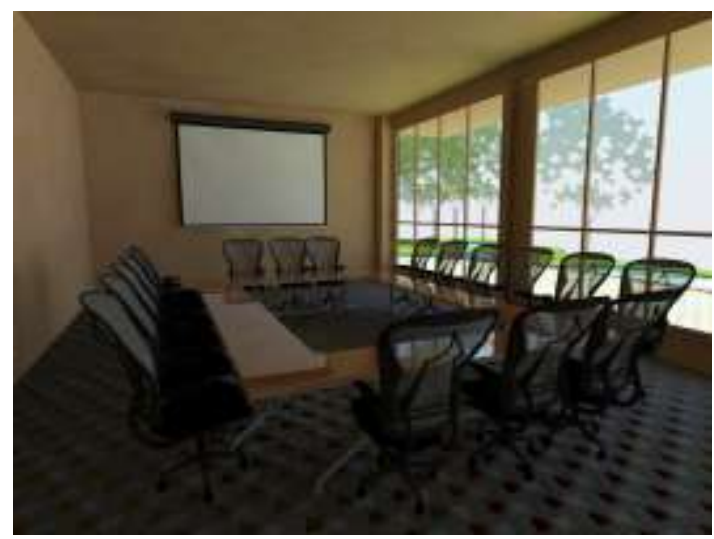

Gambar 23. Interior Ruang Rapat
(Lihat Gambar 23.), pada sisi selatan ruang rapat dimanfaatkan sebagai bukaan untuk sistem pencahayaan dan penghawaan alami. Untuk mengendalikan panasnya sinar matahari yang mungkin akan masuk ke dalam ruang, maka diberikan overhang pada bagian luar dan penggunaan gorden atau tirai serta roller blind untuk bagian dalam ruang. Selain itu, pemberian tirai ataupun roller blind juga sebagai respon saat kegiatan di dalam ruang rapat menggunakan LCD yang membutuhkan kondisi ruang yang cukup gelap.

\section{REFERENSI}

Kusumastuty, Karina Dwi, 2013, Budget Hotel di Yogyakarta.

Uddin, Maulana Arif, Bangunan Multifungsi di Surakarta dengan Pendekatan Arsitektur hemat Energi.

www.b-panel.com 


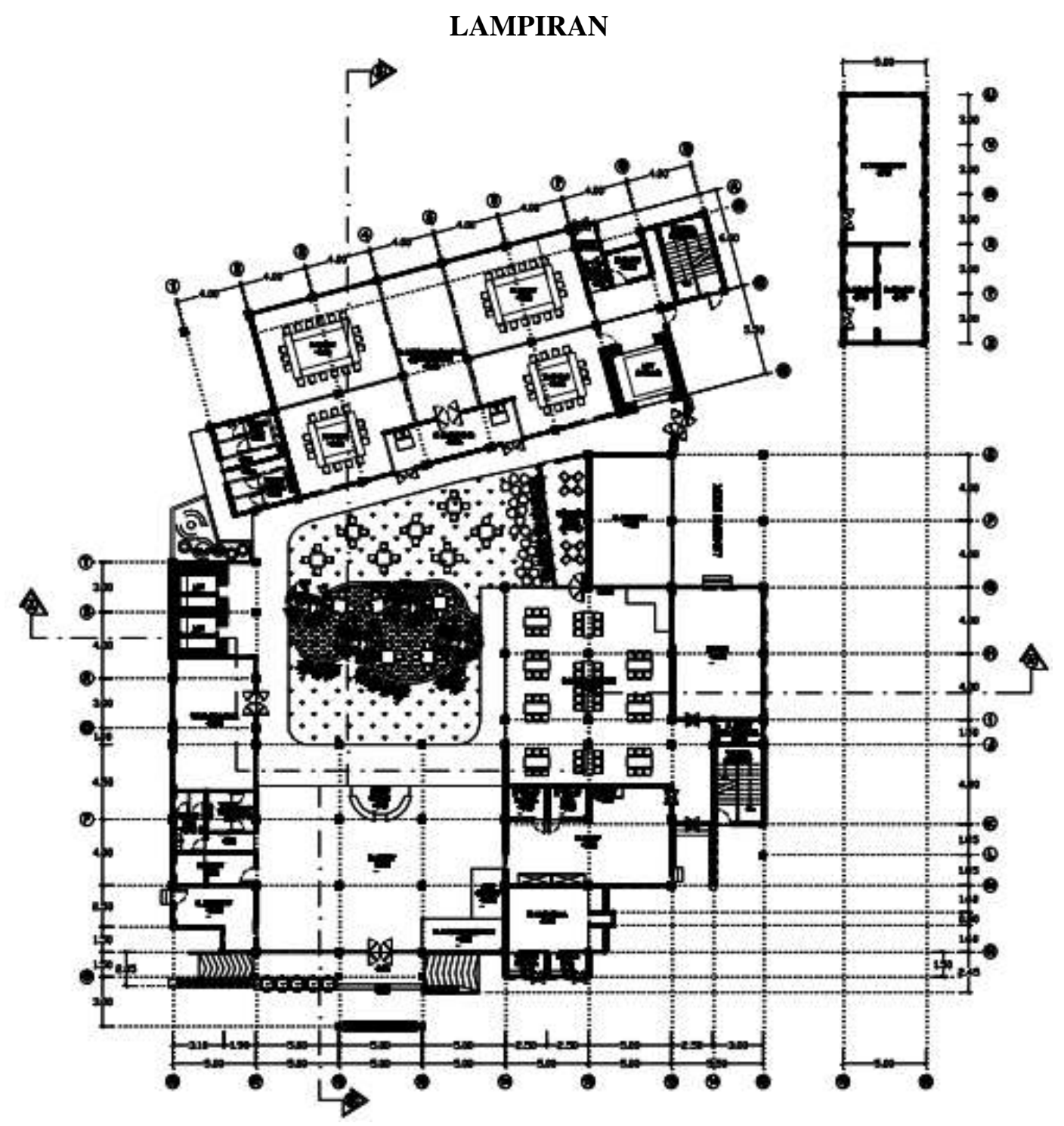

Lampiran 1. Denah Lantai Dasar

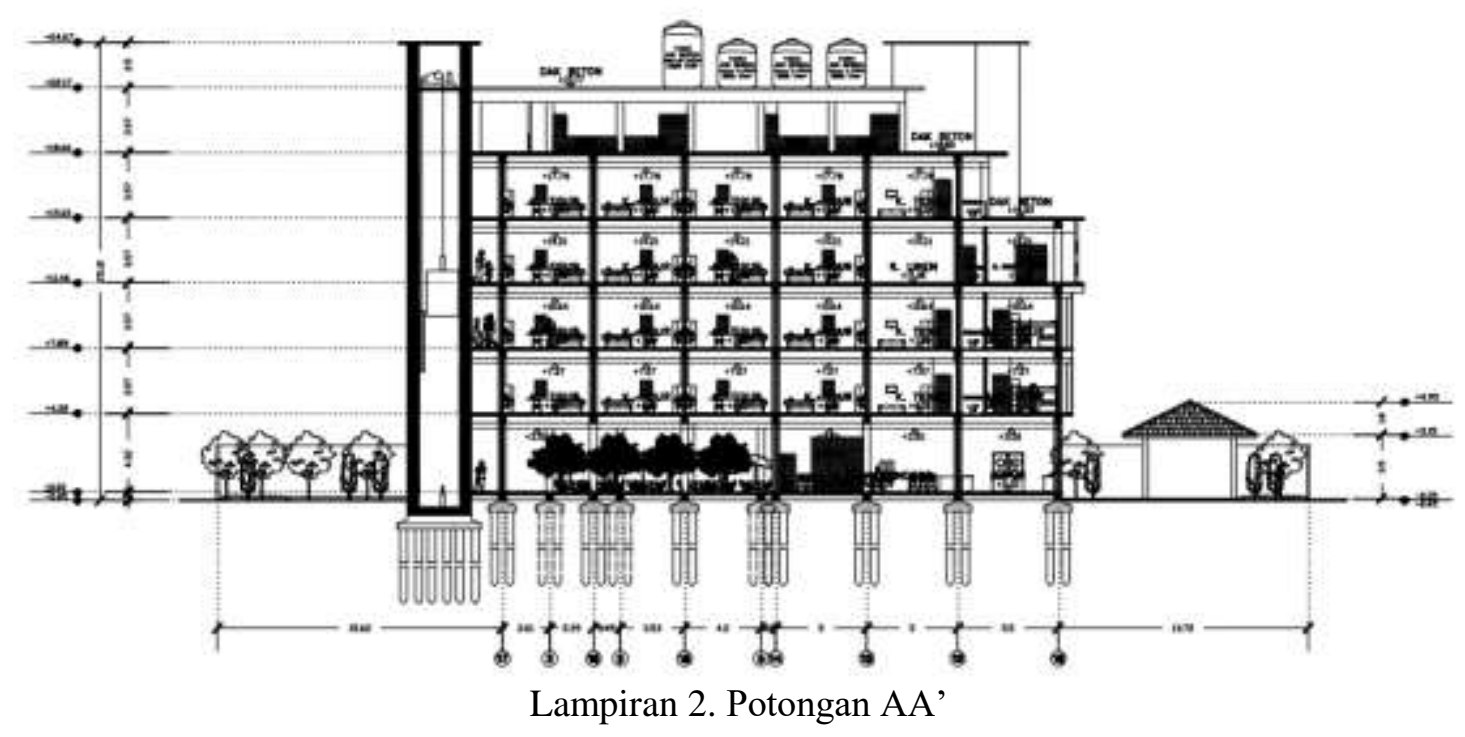

